Adıyaman Üni. Sağlık Bilimleri Derg, 2016;2(2):234-248.

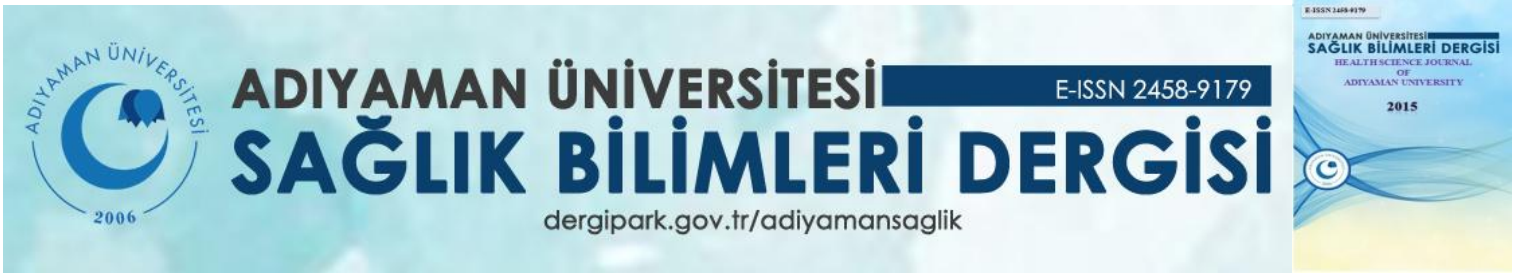

\title{
Araştırma/Research \\ Kolon Volvuluslarının Tedavisinde Mortaliteyi Etkileyen Nedenler
}

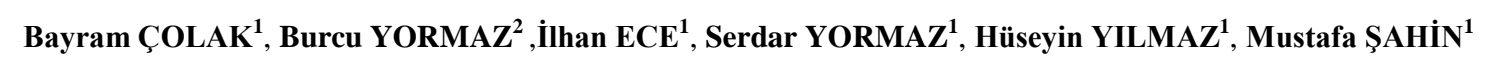

${ }^{1}$ Selçuk Üniversitesi Tıp Fakültesi Genel Cerrahi AD, Konya, Türkiye

${ }^{2}$ Selçuk Üniversitesi Tıp Fakültesi Göğüs Hastalıkları AD, Konya Türkiye

ÖZET

Amaç: Kolon volvulusları, kolon segmentinin kendi mezenteri etrafinda dönmesi olarak tanımlanmıştır. Hayatı tehdit edici olup, kısa sürede tanı konulması ve tedavi edilmesi gerekmektedir. Çalışmada, volvulus tanısı ile non-operatif veya operatif yöntemlerle tedavi edilen hastalardaki mortalite ve morbidite nedenleri incelendi.

Gereç ve Yöntem: 2010-2018 tarihleri arasında acil servisten yatırılarak tedavi edilen ileus hastaları içinden volvulus tespit edilen hastaların dosyaları geriye dönük değerlendirildi.

Bulgular: Volvulus tanısı ile 155 hasta incelendi. Hastaların 91'i (\%58.7) rezeksiyon ve anastomoz, 37'si (\%23.8) rezeksiyon ve ostomi, 27'si (\%17.4) sigmoidoskop ile dekompresyon yapilarak tedavi edildi. Hastaların 54'ünün (\%34.8) ilk değerlendirmede komplike olduğu tespit edildi. Ameliyata alınan hastaların 33'ünde (\%26) iskemik kolon, 21'inde (\%16) perforasyon, 74'ünde (\%58) normal batın bulguları ile karşılaşıldı. 92 hastada (\%59.3) post operatif dönemde operasyona bağlı komplikasyon gelişti. 33 (\%21.2) hastada yattıkları süre içinde mortalite gelişti. Mortalite gelişen hastaların yaş ortalaması 75.7 idi. Mortalite gelişen hastaların 23'ü (\%70) tekrar operasyon gereken anastomoz kaçağ hastalar idi. Bu hastaların karın içi basınç değerleri gözlendiğinde \%63.6'sında grade 4 karın içi basınç artışı tespit edildi.

Sonuç: 65 yaş üstü, ek hastalıkları olan (özellikle KOAH), karın içi basınç artışı grade 3 ve üzerinde olan komplike volvuluslarda, komplikasyon oranlarının yüksek olabileceği ve bu komplikasyonların da mortalite ile sonuçlanabileceği akılda tutulmalıdır.

Anahtar kelimeler: volvulus, mortalite, morbidite

Yazışmadan Sorumlu Yazar

DOI: 10.30569/adiyamansaglik.424312

Bayram ÇOLAK

Selçuk Üniversitesi Tıp Fakültesi Genel Cerrahi AD, Konya, Türkiye

Tel: 05301164264

Email: bayro.99@gmail.com

\begin{tabular}{ll}
\hline Geliş Tarihi: & 17.05.2018 \\
\hline Kabul Tarihi: & 14.07 .2018
\end{tabular}




\section{Causes Affecting Mortality in Colonic Volvulus Surgery}

Aim: Colonic volvulus can be determined as twistle of its own colon mesenterium. Volvulus threatens the life and should be diagnosed and treated in a short time. The causes of mortality and morbidity in patients treated with non-operative or operative methods with volvulus diagnosis were studied.

Material and method: Patients who were diagnosed as volvulus in ileus patients who were hospitalized and treated between 2010-2018 were retrospectively evaluated.

Results: 155 patients with a diagnosis of volvulus were viewed. Ninety-one (58.7\%) patients were treated with resection and anastomosis, 37 (23.8\%) with resection and ostomy, and 27 (17.4\%) with decompression with sigmoidoscopy. Complicated volvulus was found in 54 (34.8\%) patients by the initial evaluation. 33 patients $(26 \%)$ had ischemic colonic disease, 21 patients $(16 \%)$ had perforation, and 74 patients (58\%) had normal clinical findings. operation-related complications were detected in $92(\% 59.3)$ post operatively. Mortality was detected in $33(21.2 \%)$ patients during the period they were hospitalized. The meanage of the patients who found mortality was $75.7 \%$. 23 (70\%) of the patients related with mortality had anastomotic leak requiring reoperations and 28 (85\%) of these patients had multiple comorbidities. Mortality related patients had a grade 4 intraabdominal pressure increase $(63.6 \%)$.

Conclusion: It should be kept in mind that the complication rates may be higher in complicated volvulus with an over-65-year-old, especially COPD in concomitant diseases, intra abdominal pressure increase grade 3 and above, and these complications may also result in mortality.

Keywords: volvulus, mortality, morbidity 


\section{Giriș:}

Kolon volvulusları ilk olarak Rokitansky tarafından, kolon segmentinin kendi mezenteri etrafında dönmesi sonucunda obstrüksiyon oluşturması olarak tanımlanmıştır (1). İleus olgularında görülen volvulus oranı gelişmiş ülkelerde \%1-7 iken gelişmekte olan ülkelerde \%50'lere kadar çıkmaktadır (2). Kolon volvulusları hayatı tehdit edici olup kolon volvuluslarının kısa sürede doğru tanı ile tedavi edilmeleri gerekmektedir (3). Tedavide cerrahi ve cerrahi dışı yöntemler kullanılmaktadır. Cerrahi yöntemler, detorsiyon, kolopeksi, mezokoloplasti, rezeksiyon ve anastomoz, kolostomi açılması gibi yöntemlerdir (4). Cerrahi dışı yöntemler ise rektal tüp uygulaması, lavman, rijit veya fleksibıl endoskopik detorsiyon olarak tanımlanmaktadır (4). Komplike olmamış sigmoid volvuluslarda ilk tercih endoskopik detorsiyon ve bunun ardından elektif cerrahi olarak kabul edilmektedir (5). Eğer barsak gangreni, perforasyon, peritonit mevcutsa veya detorsiyon başarısız olmuş ise acil cerrahi tedavi gerekmektedir (5). Tüm bu tedavi yöntemlerine rağmen sigmoid volvulus hastalarında ortalama morbidite oranı \%12,5 iken mortalite oranı \%8-28,3 arasında değişmektedir $(1,6)$.

Çalışmada, cerrahi ve cerrahi dışı yöntemlerle tedavi edilmiş kolon volvulusu hastalarını incelemeyi, hastalarda mortalite ve morbiditeye neden olan etkenleri değerlendirmeyi amaçladık.

\section{Gereç ve Yöntemler:}

Selçuk Üniversitesi Tıp Fakültesi Genel Cerrahi Kliniği’ne 2010-2018 tarihleri arasında acil servisten yatırılarak tedavi edilen ileus hastaları değerlendirildi. Bu hastaların içinden volvulus tespit edilen hastalar retrospektif olarak incelendi. Hastalar; yaş, cinsiyet, görüntüleme bulguları, laboratuar bulguları, yapılan ameliyat çeşitleri, uygulanan ameliyat dışı yöntemleri, ilk değerlendirmede tespit edilen ameliyat öncesi komplikasyonları, 
ameliyat sonrası komplikasyonları, mortalite ve morbidite oranları ve tekrar ameliyat olma durumları açısından değerlendirildi.

Çalışmaya dahil etme kriterleri: 18 yaşından büyük, ileus bulguları olan, görüntüleme tetkiklerinde volvulus tanısı almış, volvulus nedeniyle opere edilmiş, volvulus nedeniyle dekompresyon yapılmış hastalar çalışmaya dahil edildi.

Çalışmadan çıkarma kriterleri: Volvulus olarak tanı koyulan fakat operasyonda volvulus olmadığı anlaşılan hastalar, yeterli dosya verisine ulaşılamayan hastalar çalışmadan çıkarıldı. Başka bir kurumda ameliyat edilerek kliniğimize yönlendirilen hastalar çalışmaya dahil edilmedi.

Hastaların tümü acil serviste değerlendirildi ve hepsi genel cerrahi servisinde yoğun bakım ünitesinde takip edildi. Hastaların hepsine ayakta direkt batın grafisi çekildi. Böbrek fonksiyonları normal düzeyde olan hastalara oral ve intravenöz kontrast madde verilerek tüm batın tomografisi çekildi. Böbrek yetmezliği bulguları olan hastalara kontrastsız tüm batın tomografisi çekildi. Rutin kan tetkikleri yapıldı. Genel durumu kötü, akut karın bulguları olan, görüntülemede komplike olduğu tespit edilen (perforasyon, iskemi) volvulus hastaları acil operasyona alındı. Genel durumu iyi, akut karın bulguları olmayan, komplike olmamış hastalar cerrahi dışı yöntemlerle tedavi edildi. Bu şekilde tedavisi başarısız olan hastalara yine cerrahi uygulandı. Hastaların tümü yoğun bakım ünitesinde takip edildi. Hastaların hepsine ameliyattan önce nazogastrik sonda yerleştirildi, sıvı replasman tedavisi başlandı ve hastaların hepsinin oral alımı kesildi. Nazogastrik dekompresyon yapılmadan önce hastalara hem karın içi basınç ölçümü hem de idrar takibi için idrar sondası yerleştirildi.

Karın iç basınç ölçümü (KIB): Hastalara transüretral kateter yerleştirildi. Bu kateterin ucuna üç yollu konektör bağlandı. Bu yolla mesane içine $25 \mathrm{ml}$ serum fizyolojik verildi. İçi 
tamamen serum fizyolojik ile dolu serum seti hazırlandı. Bir ucu üç yollu konektöre takıldı, supine pozisyonda yatmakta olan hastanın symphisis pubis hizası sıfır noktası olarak kabul edildi ve serum seti içindeki serum fizyolojiğin 20-30 saniye sonra hareketsiz kaldı̆̆ son nokta cetvel ile ölçüldü $(7,8)$. Normal karın içi basınç 5-7 mmHg olarak kabul edildi (8). 12 mmHg'nin üzeri karın içi basınç artışı olarak değerlendirildi (8). $1 \mathrm{mmHg}=1.36 \mathrm{~cm} \mathrm{H} \mathrm{H}_{2} \mathrm{O}$ olacak şekilde hesaplama yapıldı (9).

Abdominal hipertansiyon 4 derecede değerlendirildi (8).

Grade I: $12-15$ mmHg, Grade II: $16-20$ mmHg, Grade III: 21-25 mmHg, Grade IV: > 25 $\mathrm{mmHg}$

Cerrahi prosedür: Cerrahi prosedür olarak acil ameliyat edilen tüm hastalara rezeksiyon+anastomoz veya rezeksiyon+ostomi açılması işlemleri uygulandı. Anastomoz, rezeksiyon sonrasında kalan kolon anslarında belirgin ödem ve kanlanma bozukluğu olmayan, anastomoz yapılacak iki uç arasında ciddi çap farkı olmayan, genel durumu iyi olan, henüz komplikasyon gelişmemiş, perfüzyon problemi olmayan hastalara uygulandı. Bu kriterlerin dişında olan hastalara ostomi uygulandı.

Hastaların tümüne göbek üstü altı median kesi ile operasyon yapıldı. Rezeksiyonlar lineer stapler yardımı ile yapıldı. Anastomozlar lineer stapler ile yan yana anastomoz şeklinde yapıldı ve staplerin yerleştirildiği açık kalan segment 3/0 vicril ve 3/0 ipeklerle iki planda onarıldı. Tüm stapler hatları 3/0 ipeklerle desteklendi. Ostomiler uç kolostomi veya ileostomi şeklinde açıldı. Ostomiler cilde 3/0 ipeklerle tespit edildi. Hastaların tümüne en az bir adet nelaton dren yerleştirildi. Faysa 1 numara loop prolen ile devamlı şekilde kapatıldı. Cilt 3/0 ipeklerle tek tek kapatıldı. Ostomi açılan hastalarda, ostominin çalışması ile birlikte oral alıma başlandı. Anastomoz yapılan hastaların oral alımı için en az 3 gün beklendi, üç 
günü geçen ve gaz gaita çıkışı olan genel durumu iyi hastalara sıvı gıdalar başlandı. Bu süreye kadar bu hastalarda nazogastrik sonda tutuldu.

Detorsiyon prosedürü: Detorsiyon işlemi, fleksibıl sigmoidoskopi ile yapıldı. İşlem esnasinda aspirasyon riskinden dolayı hastalara sedasyon uygulanmadı. Detorsiyone edilemeyen olgularda 1srarcı olunmadı ve cerrahi uygulandı.

İstatistik inceleme: Veriler, Microsoft Excel 2007 (Microsoft, Redmond, WA, USA) sistemine kaydedildi ve istatistik inceleme için Statistical Package Social Sciences versiyon 20.0 programı (SPSS, Inc., Chicago, IL, USA) kullanıldı. Chi-square ve Fisher's testi grupları karşılaştırmak için kullanıldı. p<0.05 değeri istatistiksel olarak anlamlı kabul edildi.

\section{Bulgular:}

950 ileus hastasının 155 'inde (\%16.3) volvulus tespit edildi ve çalışmaya dahil edildi. Hastaların yaş ortalaması 58 (21-80) idi. 64'ü (\%42) kadın, 91'i (\%58) erkek idi. 125 hastada (\%80.6) sigmoid kolonda, 20 hastada (\%13) transvers kolonda, 10 hastada (\%6.5) çekumda volvulus tespit edildi. Hastaların tümünde KİB artışı tespit edildi. 36 (\%23.2) hastada grade 1, $42(\% 27)$ hastada grade 2, 53 (\%34) hastada grade 3, 24 (\%15.4) hastada grade 4 KİB artışı tespit edildi. Hastaların 91'i (\%58.7) rezeksiyon ve anastomoz, 37'si (\%23.8) rezeksiyon ve ostomi, 27'si (\%17.4) sigmoidoskop ile dekompresyon yapilarak tedavi edildi. Hastaların 54'ünün (\%34.8) ilk değerlendirmede komplike olduğu anlaşıldı. Ameliyata alınan hastaların 33'ünde (\%26) iskemik kolon, 21'inde (\%16) perforasyon, 74'ünde (\%58) normal batın ile karşılaşıldı. Ameliyat esnasında iskemik kolon tespit edilen hastaların 20'sine (\%60.6) rezeksiyon sonrasında anastomoz yapıldı, 13 (\%39.3) hastaya rezeksiyon sonrasında ostomi açıldı. Laparotomide iskemik kolon ile karşılaşılan ve rezeksiyon sonrasında anastomoz ile tedavi edilen hastaların 16'sında (\%80) mortalite gelişti 
$(\mathrm{P}<0.05) . \mathrm{Bu}$ hastaların \%90'ı 65 yaşın üzerinde, \%83'ü KOAH'ı olan hastalardı ve bu hastalarda en sık görülen komplikasyon anastomoz kaçağı idi (\%87). Laparotomi esnasında perforasyon tespit edilen 21 hastanın tümü rezeksiyon sonrasında ostomi açılarak tedavi edildi. Bu hastalarda mortalite oranı \%67 idi $(\mathrm{P}<0.05)$ (Tablo 1). Volvulus hastalarının acil servise başvurma süreleri ortalama 2.8 \pm 1.2 (1-5 gün) gün iken komplike volvulus tespit

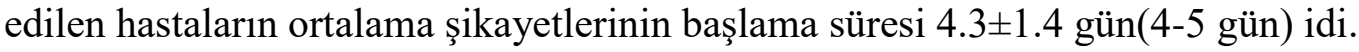

Tablo 1: Ameliyat bulgularına göre uygulanan cerrahi yöntemlerin mortalite oranları

\begin{tabular}{|l|c|c|c|c|c|c|}
\hline \multirow{2}{*}{$\begin{array}{l}\text { Ameliyat bulgusu ve } \\
\text { cerrahi yöntem }\end{array}$} & \multicolumn{2}{|c|}{ sağ } & \multicolumn{2}{c|}{ mortalite } & \multicolumn{2}{c|}{ Toplam 128} \\
\cline { 2 - 7 } & $\mathrm{n}$ & $\%$ & $\mathrm{n}$ & $\%$ & $\mathrm{n}$ & $\%$ \\
\hline Normal batın & $\mathbf{7 2}$ & $\mathbf{9 7}$ & $\mathbf{2}$ & $\mathbf{3}$ & $\mathbf{7 4}$ & $\mathbf{5 8}$ \\
\hline Rezeksiyon+anastomoz & 69 & 97 & 2 & 3 & 71 & \\
\hline Rezeksiyon+ostomi & 3 & 100 & 0 & 0 & 3 & \\
\hline İskemik kolon & $\mathbf{1 6}$ & $\mathbf{4 8}$ & $\mathbf{1 7}$ & $\mathbf{5 2}$ & $\mathbf{3 3}$ & $\mathbf{2 6}$ \\
\hline Rezeksiyon+anastomoz & 4 & 20 & 16 & 80 & 20 & \\
\hline Rezeksiyon+ostomi & 12 & 92 & 1 & 8 & 13 & \\
\hline Perfore kolon & $\mathbf{7}$ & $\mathbf{3 3}$ & $\mathbf{1 4}$ & $\mathbf{6 7}$ & $\mathbf{2 1}$ & $\mathbf{1 6}$ \\
\hline Rezeksiyon+anastomoz & 0 & 0 & 0 & 0 & 0 & \\
\hline Rezeksiyon+ostomi & 7 & 33 & 14 & 67 & 21 & \\
\hline Toplam & $\mathbf{9 5}$ & & $\mathbf{3 3}$ & & $\mathbf{1 2 8}$ & $\mathbf{1 0 0}$ \\
\hline
\end{tabular}

92 hastada (\%59.3) post operatif dönemde operasyona bağlı komplikasyon gelişti. Hastaların 43'ünde (\%51.8) yara yeri enfeksiyonu, 11'inde (\%13.2) evisserasyon, 29'unda (\%35) anastomoz kaçağı, 5'inde (\%5.4) batın içi apse, 1'inde (\%1) üreter yaralanması, 1'inde (\%1) enterokutanöz fistül, 2'sinde (\%2) derin ven trombozu gelişti (Tablo 2). Anastomoz kaçağı tespit edilen hastalarda mortalite oranı \%80'idi. Bunun yanında evisserasyon gelişen hastalar da küçük cerrahi müdahale ile evantre hale getirildi. Yara yeri 
enfeksiyonu gelişen hastaların cilt sturları alınarak drenaj sağlandı. Batın içi apse gelişen hastalara perkutan drenaj yapıld1.

Tablo 2: Hastaların postoperatif morbiditelerine göre mortalite oranları

\begin{tabular}{|l|c|c|c|c|c|c|}
\hline \multirow{2}{*}{ morbiditeler } & \multicolumn{2}{c|}{ sağ } & \multicolumn{2}{c|}{ mortalite } & \multicolumn{2}{c|}{ Toplam 92 } \\
\cline { 2 - 7 } & $\mathrm{n}$ & $\%$ & $\mathrm{n}$ & $\%$ & $\mathrm{n}$ & $\%$ \\
\hline Yara yeri enfeksiyonu & 40 & 93 & 3 & 7 & 43 & 47 \\
\hline Anastomoz kaçağ1 & 6 & 20 & 23 & 80 & 29 & 31.5 \\
\hline evisserasyon & 10 & 91 & 1 & 9 & 11 & 12 \\
\hline Batın içi apse & 4 & 80 & 1 & 20 & 5 & 5.4 \\
\hline Üreter yaralanması & 1 & 100 & 0 & 0 & 1 & 1 \\
\hline Enterokutanöz fistül & 1 & 100 & 0 & 0 & 1 & 1 \\
\hline Derin ven trombüsü & 2 & 100 & 0 & 0 & 2 & 2 \\
\hline
\end{tabular}

Tablo 3: Hastaların yaş dağılımı ve mortalite oranları

\begin{tabular}{|l|c|c|c|c|c|c|}
\hline \multirow{2}{*}{ yaş } & \multicolumn{2}{|c|}{ sağ } & \multicolumn{2}{c|}{ mortalite } & \multicolumn{2}{c|}{ Toplam } \\
\cline { 2 - 7 } & $\mathrm{n}$ & $\%$ & $\mathrm{n}$ & $\%$ & $\mathrm{n}$ & $\%$ \\
\hline $0-29$ & 23 & 100 & 0 & 0 & 23 & 14.8 \\
\hline $30-49$ & 38 & 95 & 2 & 5 & 40 & 25.8 \\
\hline $50-65$ & 54 & 93 & 4 & 7 & 58 & 37.4 \\
\hline 65 yaş üstü & 7 & 20 & 27 & 80 & 34 & 22 \\
\hline
\end{tabular}

33 (\%21.2) hastada yattıkları süre içinde mortalite gelişti. Mortalite gelişen hastaların yaş ortalaması 75.7 idi. Bu hastaların 27’si (\%82) 65 yaş üstü hastalar idi $(\mathrm{P}<0.05)$ (Tablo 3).

Mortalite gelişen hastaların 23'ü (\%70) tekrar operasyon gereken anastomoz kaçağı gelişmiş hastalar ve bu hastaların da 28'i (\%85) birden çok ek hastalığı olan hastalar idi. Bu hastalarda en çok tespit edilen ek hastalık KOAH (n:21, \%70) idi (Tablo 4). 
Tablo 4: Ek hastalıklar ve mortalite oranları

\begin{tabular}{|l|c|c|c|c|c|c|}
\hline \multirow{2}{*}{ Ek hastalıklar } & \multicolumn{2}{|c|}{ sag } & \multicolumn{2}{c|}{ mortalite } & \multicolumn{2}{c|}{ Toplam } \\
\cline { 2 - 7 } & $\mathrm{n}$ & $\%$ & $\mathrm{n}$ & $\%$ & $\mathrm{n}$ & $\%$ \\
\hline HT & 46 & 96 & 2 & 4 & 48 & 31 \\
\hline DM & 19 & 73 & 7 & 7 & 26 & 16.7 \\
\hline KAH & 7 & 70 & 3 & 30 & 10 & 6.4 \\
\hline KOAH & 9 & 30 & 21 & $\mathbf{7 0}$ & 30 & 19.3 \\
\hline
\end{tabular}

HT: Hipertansiyon, DM: Diyabetes mellitus, KAH: Koroner arter hastalığı, KOAH: Kronik obstruktif akciğer hastalığı

KOAH'1 olan hastaların 28'inde (\%93.3) volvulus tanısı ile birlikte akciğer fonksiyonlarında da ileri derecede bozukluk tespit edildi. Mortalite gelișen KOAH'lı hastaların tümü ileri derecede akciğer fonksiyon bozukluğu tespit edilen hastalar idi. $\mathrm{Bu}$ hastaların karın içi basınç değerleri gözlendiğinde 21 hastada (\%63.6) grade 4, 9 hastada (\%27.2) grade 3 ve 3 hastada (\%9) grade 2 karın içi basınç artışı mevcuttu.

\section{Tartışma:}

Barsak obstrüksiyonları, genel cerrahinin majör abdominal cerrahi gerektiren acillerindendir. Çalışmada özellikle gelişmekte olan ülkelerde kolon obstrüksiyonlarının büyük çoğunluğunun etyolojisinden sorumlu olan volvulus hastalarını ele aldık. Konu olarak çalışmamız güncelliğini korumaktadır. Fakat çalışmanın retrospektif olması, hasta sayısının yüksek olmaması, ameliyat ve girişimlerin tek cerrah tarafından yapılmış olmaması gibi olumsuz yönleri bulunmaktadır. Makale incelenirken bu kısıtlayıcı yönlerin akılda bulundurulması faydalı olacaktır.

Volvulus, kolon ansının kendi mezenteri etrafinda en az 180 derece dönmesi durumudur (9). Volvuluslar en sık sigmoid kolonda, sonra sırasıyla çekum, splenik fleksura, transvers kolon ve inen kolonda görülür (10). Etyolojisi tam olarak aydınlatılamamakla birlikte 
sosyoekonomik durumu kötü, kırsal bölgelerde yaşayan kişilerde sıklıkla görülmekte ve bu durumun bol posalı ve selülozdan zengin diyet alışkanlığı ile bağlantılı olduğu belirtilmektedir (10). Bunun yanında dar mezenterik tabanlı kolon yapısı, kronik konstipasyon, kolonun motilite bozukluğu, yaşl1lık, anatomik etkenler gibi birçok neden de sorumlu tutulmaktadır $(11,12)$. Transvers kolon volvulusları, volvuluslar içinde milyonda 2.8-7.1 oranı ile nadir rastlanan türdendir (13). Çalışmada, literatürün aksine \%80,6 sigmoid, \%13 transvers, \% 10 çekal volvulus tespit edildi. Bu farklılığın verilerine tam olarak ulaşılamayan hastalarımızın bir kısmının çekal volvulus olgusu olmasına bağlamaktayız.

Sigmoid volvuluslar 40 yaş üzeri erkeklerin hastalığıdır (14). Erkek ve kadınlarda görülme oranı 1.4/1 ile 4/1 arasında değişmektedir $(6,1)$. Çalışmada bulgular literatür ile uyumluydu.

Preoperatif dönemde volvulus tanısını, sigmoidoskopi, bilgisayarlı tomografi (BT), manyetik rezonans (MR) gibi görüntüleme tetkiklerini kullanmadan koymak zordur $(6,1,15)$. Çalışmada, hastaların tanılarının ayakta direkt batın grafisi (ADBG), BT ile konulduğu tespit edildi. ADBG volvulus tanısı için yeterli olsa da hastalara mutlaka BT gibi ikinci bir tetkik kullanıldı. Çünkü X-ray tetkikleri tanı için spesifik olmayan bulguları göstermekte fakat etyolojide yardımcı olmamaktadır. Çalışmalarda X-ray incelemelerinin \%30-40 oranında tanı koydurucu olamadığ süperpoze olması veya bunların sigmoid volvulusu taklit etmesi X-ray grafilerinin başarısız olmasının nedenlerindendir $(17,18)$. Bu nedenle hastalarımızın tümüne X-ray incelemesinin yanında BT gibi görüntüleme tetkiki de yapıldı.

Yapılan çalışmalarda volvulus hastalarında mortaliteyi etkileyen risk faktörleri belirtilmiştir. Bir çalışmada mortalite gelişen volvulus hastalarının \%72,6'sının 60 yaş üstü olduğu $(19,20)$, bunun yanında Arnold ve Nance'nin çalışmalarında mortalite gelişen hastaların 
3/4'ünün 70 yaş üstü olduğu belirtilmiştir (21). Çalışmada, mortalite tespit edilen hastaların yaş ortalamaları 70,6 olarak tespit edildi.

Volvulus, çeşitli kardiovaskuler, respiratuvar, renal ve diğer organ hastalıkları ile birlikte görünmektedir ve mortalite üzerine yüksek oranda etkili olduğu bilinmektedir $(19,21)$. Çalışmada, hastalarda birçok ek hastalık tespit edildi. Birden çok ek hastalığı olanlarda (bunların içinde KOAH yüksek oranda) ve KOAH'1 olan hastalarda mortalite oranının diğerlerine göre anlamlı olarak yüksek (\%63.3) olduğu görüldü. Bu durumun KİB artışının zaten $\mathrm{KOAH}$ ve akciğer problemi olan hastalarda diaframın toraksa doğru yer değiştirmesi sonucu akciğer kompliyansındaki azalmaya bağlamaktayız.

Çalışmamızda peritonit ve akut karın bulguları olmayan hastalarda ilk tedavi seçeneği sigmoidokopi yardımı ile detorsiyon olmuştur. Sigmoid, çekum ve transvers kolon volvuluslarının tümünde detorsiyon denenmiştir. Fakat çalışmada detorsiyonun başarı oranı \%17.4 olmuştur. Detorsiyon yapılan hastaların da \%85'i elektif ameliyat planlanıncaya kadar tekrar torsiyone olmuş ve bu hastalara cerrahi tedavi uygulanmıştır. Çalışmalarda da komplike olmamış volvulusların tümünde ilk tedavi seçeneğini sigmoidoskopi ile detorsiyon olarak tanımlanmıştır (22). Endoskopik girişimlerle sigmoid kolon volvuluslarının \%7689'unun, çekum volvuluslarının \%50'sinin başarılı bir şekilde detorsiyon yapıldığı fakat bu hastaların \%21-57'sinde nüks tespit edildiği belirtilmektedir $(23,24)$. Yine başka bir literatürde detorsiyon sonrası nüks oranı \%40-90 olarak belirtilmiştir $(25,26)$. Bu nedenle detorsiyon işlemi yapılmış tüm hastalara kısa süre içinde operasyon önerilmelidir.

Uygulanacak cerrahi yöntemler hakkında fikir birliği bulunmamaktadır. Basit detorsiyon ve detorsiyon ile birlikte kolonun karın duvarına fiksasyonu önerilen yöntemlerdendir. Fakat bu yöntemlerde nüks oranının yüksek olduğu ve mortalite geliştiği bildirilmektedir (6). Ekstraperitonealizasyon ve mezokoloplasti yöntemleri tanımlanmıştır fakat bu yöntemlerin 
de nüksü önlemedeki etkileri kanıtlanamamıştır $(6,19)$. Çalışmada hastaların hiç birine bu yöntemler uygulanmamıştır. Endoskopik detorsiyon yapılan hastaların tümü kısa süre içinde elektif cerrahi işlem için çağırılmıştır. Elektif cerrahide hastaların tümüne rezeksiyon ve anastomoz yapıldı. Nüksü önlemedeki en etkili yöntem rezeksiyondur, iskemik olmayan kolonlar için mortalite ve morbiditesi düşük olarak bilinmektedir $(19,28)$. Bunların yanında volvulus hastalarında tedavi yöntemleri; hastanın yaşı, ek hastalıkları, şikayetlerinin başlangıç süresi, lökosit değeri, kolonda gangren veya nekroz olması gibi faktörlere göre seçilmektedir. Rezeksiyon ve anastomoz daha genç, hastaneye erken başvurmuş, komplike olmamış, kolon ansları arasında ciddi çap farkı oluşmamış hastalara uygulanırken, ileri yaşlı, ek hastalıkları olan, komplike hastalar rezeksiyon ve ostomi açılması işlemleri ile tedavi edildi. Çalışmalarda kolonun beslenmesi iyi olarak tespit edilmiş hastalarda rezeksiyon sonrası anastomoz ile ostomi açılması arasında mortalite ve morbidite açısından fark görülmemiştir (29). Bunun yanında nekrotik ve komplike olmuş hastalarda hartman prosedürü daha az mortalite ile sonuçlanmıştır (10). Çalışmada komplike olmamış ve iskemi görülmemiş olgularda rezeksiyon ve anastomoz yapıldı. Hastaların \%58,7'si rezeksiyon ve anastomoz ile tedavi edilirken, $\% 23.8$ 'i rezeksiyon ve ostomi ile tedavi edildi. Anastomoz yapılan hastaların \%35'inde anastomoz kaçağı tespit edildi. Kaçak tespit edilen hastalar değerlendirildiğinde bu hastaların yaş ortalaması 67.3 idi. \%83'ünde $\mathrm{KOAH}$ ve birden çok ek hastalık vardı. Bu hastaların şikayetlerinin başlamasından hastaneye gelinceye kadar geçen süreleri 4.2 gün idi. Çalışmalarda, semptom süresinin 24 saatin üzerinde olmasının mortaliteyi arttırdığı bildirilmiştir $(19,30)$. Çalışmada anastomoz kaçağı gelişen hastaların tümü mortal seyretti.

Birçok yazarın belirttiği gibi volvuluslarda en önemli mortalite nedenlerinden birisi kolon gangrenidir $(6,19,31)$. Başka bir çalışmada kolonda gangren oluşmuş hastalarda mortalite oranı \%80 olarak bildirilmiştir (32). Çalışmada komplike olmuş hastaların operasyonunda 
\%61 oranında gangren tespit edildi. Bu hastalarda mortalite oranı literatür ile benzer şekilde idi.

Karın içi basınç artışı (KİB) sonucu gelişen abdominal kompartman sendromunun önemli bir mortalite ve morbidite nedeni olduğu bilinmektedir $(33,34)$. Çok fazla ekspanse olamayan karında, intraabdominal kompartmandaki basınç artışı öncelikle kapiller dolaşımda, daha sonra venöz ve arterial dolaşımda değişikliklere neden olmaktadır (35). KİB'ın 20 mmHg'nin üzerine çıkması ile kapiller yatağın perfüzyonunda düşüş ve dokularda iskemi görülmektedir (35). Barsaklar KİB artışına en hassas organlardandır (36). Mezenterik hipoperfüzyon, intestinal ödem, iskemi ve bakterial translokasyona neden olur (36,37). KİB artışı, diaframı yukarı doğru iterek total akciğer kapasitesini kısıtlamakta ve fonksiyonel rezidüel kapasiteyi azaltmaktadır (38). Ayrıca diaframın yukarı doğru itilmesi ile akciğer alt loblarında atelektazi meydana gelmesi sonucu oksijenizasyon bozulmakta, hiperkarbi ve ventilasyon bozukluğu oluşmaktadır (35). Çalışmada hastaların tümünde karın içi basınç artışı mevcuttu. Bu hastaların \%50'sinde KİB 20 mmHg'nin üzerinde idi. Mortalite gelişen hastaların \%95'inde KİB 20 mmHg'nin üzerine ölçüldü. KOAH tanısı olan hastaların \%93,3'ünde volvulus ile birlikte akciğer fonksiyonlarında bozulma ve mortalite tespit edildi.

\section{Sonuç:}

Volvulus nedeniyle cerrahi veya cerrahi dışı yöntemlerle tedavi edilecek hastaların iyi seçilmesi ve cerrahi prosedürün iyi belirlenmesi gerekmektedir. 65 yaş üstü, ek hastalıkları olan özellikle KOAH'ı olan, karın içi basınç artışı grade 3 ve üzerinde olan komplike volvuluslarda, komplikasyon oranlarının yüksek olabileceği ve bu komplikasyonların da mortalite ile sonuçlanabileceği akılda tutulmalıdır. 65 yaş üzeri, ek hastalıkları olan, laparotomide kolonda iskemi tespit edilmiş hastalarda batın içi kirlenme olmasa bile 
anastomozdan kaçınılması ve rezeksiyon sonrasında ostomi ile tedavi edilmesi, anastomoz kaçağı riskini ve bunun beraberinde gelişebilecek mortalite riskini düşürebilecektir. Özellikle hastaneye başvuru süresi 4 gün ve üzerinde olan volvulus hastaları değerlendirilirken komplike olmuş bir volvulus tablosu ile karşılaşılabileceği akılda tutulmalıdır.

\section{Kaynaklar:}

1. Raveenthiran V, Madiba TE, Atamanalp SS, De U. Volvulus of the sigmoid colon. Colorectal Dis. 2010;12(7):1-17.

2. Jones DJ. ABC of colorectal diseases. Large bowel volvulus BMJ 1992;305(6849):358-60.

3. Mulas C, Bruna M, García-Armengol J, Roig JV. Management of colonicvolvulus. Experience in 75 patients. Rev Esp Enferm Dig 2010;102:239-48.

4. Yakan S, Şirinocak A, Telciler K E, Yılmaz S, Deneçli A G. Kolon volvulusları: Süregelen problem ve tedavi seçenekleri. Ege Tip Derg 2009;48: 89-93.

5. Atamanalp SS, Atamanalp RS. The role of sigmoidoscopy in the diagnosis and treatment of sigmoid volvulus. Pak J MedSci.2016;32(1):244-248.

6. Oren D, Atamanalp SS, Aydinli B, Yildirgan MI, Basoglu M, Polat KY, et al. An algorithm for the management of sigmoid colon volvulus and the safety of primaryResection: Experience with 827 cases. Dis Colon Rectum. 2007;50(4):489-497.

7. Kron IL, Harman PK, Nolan SP. The measurement of intra-abdominal pressure as a criterion for abdominal re-exploration. Ann Surg 1984; 199: 28-30.

8. Malbrain ML, Cheatham ML, Kirkpatricl A. Et al. Results from the International Conference of Experts on Intra-abdominal Hypertension and Abdominal Compartment Syndrome. I. Definitions Intensive Care Med 2006; 32:1722-1732

9. Parsak CK. Komplike abdominal infeksiyonlarda abdominal kompartman sendromu. ANKEM Derg 2012; 26 (ek 2): 337-348.

10. Lau KCN, Miller BJ, Schache DJ, Cohen JR. A Study large bowel volvulus in urban Australia. Can J Surg 2006; 49: 203-207.

11. Madiba T, Thomson S. The management of caecal volvulus. Dis Colon Rectum 2002;45:264-7.

12. Margolin DA, Whitlow CB. The pathogenesis and etiology of colonic volvulus. Semin Colon Rectal Surg 1999; 10:129-38.

13. Yaseen $\mathrm{ZH}$, Watson RE, Dean HA, et al. Case report: transverse colon volvulus in a patient with Clostridium difficle pseudomembranous colitis. Am J Med Sci. 1994;308:247-50.

14. Rokitansky C. Intestinal strangulation. Arch Gen Med 1837;14:202-204.

15. Atamanalp SS. Sigmoid volvulus: Diagnosis in 938 patient sover 45.5 years. Tech Coloproctol. 2013;17(4):419-424

16. Atamanalp SS, Kantarci A, Ozogul B, Kisaoglu A, Atamanalp RS. The role of CT and MRI in the diagnosis of sigmoid volvulus. Turk J Med Sci. 2014;44(2):352. 
17. Catalano O: Computed tomographic appearance of sigmoid volvulus. Abdom Imaging 1996, 21(4):314317.

18. Ott DJ, Chen MYM: Specific acute colonic disorders. Radiol Clin North Am 1994, 32:871-884.

19. Young WS, Engelbrecht HE, Stocker A: Plain film analysis in sigmoid volvulus. Clin Radiol 1978; 29:553-560.

20. Bhatnagar BNS, Sharma CLN, Gautam A, Kakar A, Reddy DCS. Gangrenous sigmoid volvulus: a clinical study of 76 patients. Int J ColorectalDis 2004; 19: 134-42.

21. Arnold GJ, Nance FC. Volvulus of the sigmoid colon. Ann Surg 1973; 177: 527-37.

22. Oncu M, Piskin B, Calik A, Yand1 M, Alhan E. Volvulus of the sigmoid colon. South Afr J Surg 1991; 29: 48-9.

23. Kuzu MA, Aslar AK, Soran A, et al. Emergent resection for acute sigmoid volvulus: results of 106 consecutive cases. Dis Colon Rectum 2002;45:1085-90.

24. Hiltunen KM, Syrja H, Matikainen M. Colonic volvulus. Diagnosis and results of treatment in 82 patients. Eur J Surg. 1992; 158: 607-611.

25. Grossmann EM, Longo WE, Stratton MD, et al. Sigmoid volvulus in Department of Veterans Affairs Medical Centers. Dis Colon Rectum 2000; 43: 414-418.

26. Brothers TE, Strodel WE, Eckhauser FE. et al.Endoscopy in colonic volvulus. Ann Surg 1987;206:1-4.

27. Gibney EJ. Volvulus of the sigmoid colon. Surg Gynecol Obstetrics 1991; 173:243-248.

28. Akgun Y. Mesosigmoplasty as a definitive operation treatment of acute sigmoid volvulus. Dis Colon Rectum 1996; 39: 579-581.

29. Naaeder SB, Archampong EQ. One stage resection of acute sigmoid volvulus. Br J Surg. 1995; 82: 1635 1636.

30. Chang JG, Shelton A, Welton ML. In: Volvulus: Dogherty GM, Way LW, Editors. Surgical Diagnosis and treatment. 10th ed. Connecticut Appletonand Lance; 1994. p. 675-7.

31. Dulger M, Canturk NZ, Utkan NZ, Gonullu NN. Management of sigmoid colon volvulus. Hepatogastroenterology 2000; 47:1280-3.

32. Bhuiyan MM, Machowski ZA, Linyama BS, Modiba MC. Management of sigmoid volvulus in Polokwane-Mankweng Hospital. S Afr J Surg 2005; 43: 17-9.

33. Atamanalp SS, Yildirgan MI, Basoglu M, Kantarci M, Yilmaz I. Sigmoid colon volvulus in children: review of 19 cases. Pediatr SurgInt 2004; 20: 492-5.

34. Kirkpatrick AW, Roberts DJ, De Waele J, Jaeschke R, Malbrain ML, De Keulenaer B, et al. Intraabdominal hypertension and the abdominal compartment syndrome: updated consensus definitions and clinical practice guidelines from the World Society of the Abdominal Compartment Syndrome. Intensive care medicine2013;39:1190-1206.

35. Cheatham ML. Abdominal compartment syndrome. Curr Opin Crit Care 2009;15:154-162.

36. Carr JA. Abdominal compartment syndrome: a decade of progress. J Am Coll Surg 2013;216:135-146.

37. Ameloot K, Gillebert C, Desie N, Malbrain ML. Hypoperfusion, shock states, and abdominal compartment syndrome (ACS). Surg Clin North Am 2012;92:207-220.

38. An G, West MA. Abdominal compartment syndrome: a concise clinical review. Crit Care Med 2008;36:1304-1310. 